\title{
In-vitro antisickling and sickling-reversal activities of Carica papaya fruit at different stages of ripening
}

\author{
Adetayo $\mathrm{MO}^{1}$, Shokunbi OS ${ }^{1}$, Oyelese $\mathrm{AT}^{2}$, Adetayo $\mathrm{AM}^{3}$ \\ ${ }^{1}$ Department of Biochemistry, School of Basic Medical Sciences, Babcock University, Nigeria. \\ ${ }^{2}$ Department of Haematology, School of Basic Clinical Sciences, Babcock University Nigeria. \\ ${ }^{3}$ Department of Surgery, School of Clinical Sciences, Babcock University, Nigeria.
}

\begin{abstract}
Objective: Sickle cell disease (SCD) is a haemoglobinopathy that causes several clinical complications. Unripe Carica papaya has been shown to possess antisickling activity that could reduce these complications. This study aimed to examine the presence of antisickling and sickling-reversal activities of aqueous extracts and ethyl acetate fractions of $C$. papaya fruit at different stages of ripening.

Methods: Unripe, partly ripe and fully ripe fruits were quantitatively screened for some phytochemicals using standard methods. Blood samples from sickle cell patients were used to investigate antisickling and sickling reversal activities of aqueous extracts and ethyl acetate fractions of the fruits. Data were analysed using one-way ANOVA. p-value was set at 0.05 .

Results: Phytochemicals such as alkaloids, saponins, tannins, flavonoids and polyphenols were found in varying concentrations in C. papaya fruit at the different stages of ripening. All extracts and fractions showed antisickling and sickling-reversal activities with the ethyl acetate fraction of partly ripe C. papaya being most effective. Conclusion: The study showed that C. papaya fruit at different stages of ripening contains antisickling and sicklingreversal activities which may help reduce the associated complications of SCD when consumed by affected individuals.
\end{abstract}

Keywords: Anti-sickling, Sickling-Reversal, Phytochemical, Carica papaya

\section{Background}

Sickle-cell disease (SCD) is a genetic disorder that occurs due to the presence of abnormal hemoglobin $(\mathrm{HbS})$ in red cells which is caused by the replacement of glutamic acid with valine. This results in the transformation of the bi-convex shape of red blood cells into sickle shape under certain unfavorable conditions including hypoxia, stress, and dehydration (1). It is a multisystemic disease characterized by the premature breakdown of red blood cells leading to constant anemia and vaso-occlusion which results in severe body pains and other manifestations. Sickled erythrocytes tend to block capillaries, causing stasis, and thereby starve organs of both nutrients and oxygen and eventually cause hypofunction or complete tissue destruction (2). Management of SCD involves the use of medications like hydroxycarbamide, also known as hydroxyurea, reduces the frequency of painful crises, and may also reduce the need for blood transfusions by stimulating the production of fetal hemoglobin (3). Analgesics, antimalarial, antibiotics and antioxidants are also commonly used as supportive drugs (4). Research into the efficacy of plants in the management of SCD has evolved. A commonly used herbal drug with antisickling properties, Niprisan, is essentially 
plant-based (5). More recently, studies $(6,7)$ have shown that phytomedicines are very effective as antisickling and sickling-reversal agents.

Research on the antisickling activities of two ethnomedicinal plant recipes used in the treatment of SCD in Ibadan, Nigeria, showed that the methanol extracts of the powdered plant parts displayed antisickling activities in vitro. Confirmation of the antisickling activity in the two recipes justified their use in the treatment of the disease. Phytochemical screening of the extracts showed that they contained similar bioactive compounds and each recipe was composed of several plant species, including C. papaya (8). C. papaya Linn, commonly known as Pawpaw, is a tropical fruit belonging to the plant family Caricaceae and the genus Carica native to Mexico and Central America. Different parts of the C. papaya plant such as the seeds, leaves, pulp, stem, bark, and root have been used for medicinal purposes and as nutraceutical fruits in the management of many diseases (9). This is said to be due to the presence of various phytochemicals, vitamins and mineral elements which they contain and these attributes have been reported to confer on the plant, astringent, analgesic, anti-helminthic, anti-bacterial, antioxidant, hypoglycemic, antifungal, antisickling, nephroprotective, and other pharmacological properties (8). Phytochemical screening of different parts of unripe C. papaya revealed the presence of bioactive compounds such as alkaloids and flavonoids, among others (10).

The complications of SCD are life-threatening and a lot of efforts have been made to manage the disease, especially through the use of drugs that will prevent sickling of red cells that are usually the cause of crises. However, the cost implications and possible toxicity of these drugs constitute a major hindrance to SCD management (11). Therefore, potential management of SCD with a sweet, edible fruit like pawpaw offers a potential means of avoiding the use of drugs with its attendant complications. $C$. papaya is a common plant growing naturally in the community of Ilishan-Remo, Ogun State. There is a dearth of investigation comparing the antisickling activity of $C$. papaya at different ripening stages.

This study aimed to investigate the antisickling and sickling-reversal activities of aqueous extracts and ethyl acetate fractions of unripe, partly ripe, and fully ripe $C$. papaya fruit pulp (CPFP).

\section{Methods}

Ten sickle cell patients who have not had any crises in the last 72 hours were recruited, from the Haematology Unit of Babcock University Teaching Hospital for the study. The research protocol was carefully explained to the participants after which they signed a written consent form to indicate their interest in participating. The research was carried out between March and October 2019 at the Department of Biochemistry, Babcock University, Ilishan-Remo, Ogun State, Nigeria. Babcock University is located at llishan-Remo, equidistant between Ibadan and Lagos. The department of Biochemistry ventures into research in the areas of Phytomedicine, Clinical Biochemistry, Toxicology, Molecular Biology, Biotechnology, and Human Nutritional Biochemistry.

Following authentication, fresh $C$. papaya fruits were collected directly from the C. papaya tree at the specific stages of ripening; unripe, partly ripe, and fully ripe. The unripe fruit was defined by the completely green color of the exocarp and the white color of the flesh. The partly ripe fruit was defined by the partly green and partly yellowish color of the exocarp and the light yellow color of the flesh. The fully ripe fruit was defined by the completely yellow color of the exocarp and the orange-red color of the flesh (12). Subsequently, the fruits were peeled, the seeds inside were removed and the fruit pulps were washed with distilled water and kept in a refrigerator, in preparation for analyses.

Preparation of Aqueous Extracts and Ethyl Acetate Fractions of C. papaya fruit Pulp

One hundred grams each of unripe, partly ripe, and fully ripe $C$. papaya fruit pulp were diced into separate beakers and $100 \mathrm{~mL}$ of distilled water was added to each beaker to soak its content at room temperature for 48 hours. The content of each beaker was then filtered using a filter paper (Whatman No. 1, 125mm, England) and the filtrates were collected as the aqueous extract of unripe, partly ripe, and fully ripe C. papaya fruit. Similarly, $100 \mathrm{~g}$ each of unripe, partly ripe and fully ripe $C$. papaya fruit were diced into different beakers, soaked with $100 \mathrm{~mL}$ of methanol (BDH Chemicals, Bois-Franc, Canada) and kept at room temperature for 48 hours. The content of each beaker was concentrated to dryness using a rotary evaporator (RE-1050, Shanghai Yuhua Instrument Equipment CO., China) to obtain the crude methanol extract (13). The crude methanol extract was then reconstituted in distilled water and partitioned with ethyl acetate $(\mathrm{BDH}$ 
Chemicals, Bois-Franc, Canada) to obtain the ethyl acetate fraction of unripe, partly ripe and fully ripe $C$. papaya fruits.

\section{Blood Sample Collection and Processing}

Ten milliiters of blood was collected from each participant by venipuncture, following the method described by Whitehead (14), and transferred immediately into EDTA bottles. Each sample was subjected to antisickling and sickling-reversal tests within 48 hours of collection. The blood samples were stored at $4-8{ }^{\circ} \mathrm{C}$ during the period of study. A control experiment was set-up which contained phosphate buffer in place of the extracts and fractions.

\section{Quantitative Phytochemical Analysis}

The unripe, partly ripe, and fully ripe $C$. papaya fruit pulps were prepared for phytochemical screening using the method of Oloyede (15). The peeled fruits were chopped and oven-dried at $40^{\circ} \mathrm{C}$ and then ground with an electric grinder. The resulting powdered samples were stored in properly sealed bottles at $4^{\circ} \mathrm{C}$ in a refrigerator. These were quantitatively analyzed for alkaloid, saponin, tannin, total phenol, and flavonoid contents.

\section{Determination of Alkaloid Content}

The alkaloid content was estimated using the method described by Harborne (16). Forty milliliters of $20 \%$ acetic acid in ethanol was added to $5 \mathrm{~g}$ of the powdered sample, covered and allowed to stand for 4 hours and subsequently subjected to filtration with a filter paper. The filtrate was then concentrated on a water bath to $10 \mathrm{~mL}$. Concentrated ammonium hydroxide (BDH Chemicals, Bois-Franc, Canada) was added dropwise to the filtrate until the precipitation was complete. The whole suspension was then allowed to settle and the resulting precipitate was washed with dilute ammonium hydroxide (Sigma Aldrich Chemicals Company, Missouri, United States) and filtered. The residue was dried in the oven (Uniscope SM9053 Oven, Surgifield Medicals, Oakhampton UK) at $60^{\circ} \mathrm{C}$ and weighed. Percentage composition of alkaloid was calculated as follows:

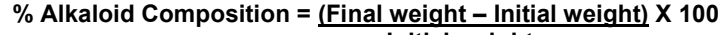
Initial weight

\section{Determination of Saponin Content}

Saponin content was determined using the method of Obadoni and Ochuko (17). Twenty grams of the powdered sample was put into a conical flask containing $100 \mathrm{~mL}$ of $20 \%$ aqueous ethanol. The sample was heated over a hot water bath for 4 hours with continuous stirring at about $55^{\circ} \mathrm{C}$. The mixture was then filtered and the residue re-extracted with another $200 \mathrm{~mL}$ of $20 \%$ ethanol (BDH Chemicals, Bois-Franc, Canada). The combined extract was reduced to $20 \mathrm{~mL}$ over a water bath at $90^{\circ} \mathrm{C}$. The concentrate was transferred into a $250 \mathrm{~mL}$ separating funnel and $20 \mathrm{~mL}$ of diethyl ether was added (to remove the fat) and shaken vigorously. The aqueous layer was recovered while the ether layer was discarded. This purification process was repeated thrice. Sixty milliliters of $n$-butanol (BDH Chemicals, Bois-Franc, Canada) were then added. These combined n-butanol-aqueous extracts were washed twice with $10 \mathrm{~mL}$ of $5 \%$ aqueous sodium chloride. The remaining solution was heated in a water bath. After evaporation, the sample was dried in the oven at $40^{\circ} \mathrm{C}$ to a constant weight and the percentage Saponin content was calculated as follows:

$\%$ Saponin content $=($ Final weight - Initial weight $) \times 100$ Initial weight

\section{Determination of Tannin content}

This was done using Vanillin-HCL method (16) in which $0.2 \mathrm{~g}$ of powdered sample was extracted with $10 \mathrm{~mL}$ of methanol at $30^{\circ} \mathrm{C}$. One milliliter of the resulting extract was reacted with $5 \mathrm{~mL}$ of acidified vanillin reagent (50:50 mixtures of $1 \%$ vanillin and $8 \% \mathrm{HCl}$ in methanol) at $30^{\circ} \mathrm{C}$ for 20 minutes after which absorbance was read at 500 $\mathrm{nm}$. For blank, $4 \% \mathrm{HCl}$ was added to the extract instead of vanillin reagent, and absorbance was also read at $500 \mathrm{~nm}$. Blank value was subtracted from experimental values to give adjusted data. Catechin was used as standard, and a catechin standard curve from 0.0 to $1.0 \mathrm{mg} / \mathrm{mL}$ in $0.2 \mathrm{mg}$ increment was used to calculate tannin levels. The tannic acid content was expressed in terms of milligram catechin equivalent per 100-gram dry weight of the sample.

\section{Estimation of Total Phenol}

The total phenol content in different solvent extracts was determined using a procedure reported by Singleton, Orthofer, and LamuelaRaventos (18). Appropriate dilutions of the extracts were mixed with $2.5 \mathrm{~mL}$ of $10 \%$ FolinCiocalteau's reagent (v/v) and neutralized by 2.0 $\mathrm{mL}$ of $7.5 \%$ sodium carbonate. The reaction mixture was incubated for $40 \mathrm{~min}$ at $45^{\circ} \mathrm{C}$ and the absorbance was measured at $765 \mathrm{~nm}$. The total phenol content was subsequently calculated using gallic acid as standard expressed in terms 
of milligram gallic acid equivalent per 100 grams' dry weight of the sample.

\section{Determination of Flavonoid content}

The amount of total flavonoid content was determined by the Aluminum chloride method (19). The reaction mixture $(3.0 \mathrm{~mL})$ comprised 1.0 $\mathrm{mL}$ of extract, $0.5 \mathrm{~mL}$ of aluminum chloride $(1.2 \%)$ and $0.5 \mathrm{~mL}$ of potassium acetate $(120 \mathrm{~mm})$ was and $1 \mathrm{~mL}$ of methanol. This was incubated at room temperature for 30 minutes and the absorbance was measured at $415 \mathrm{~nm}$. Quercetin (Sigma Aldrich Chemicals Company, Missouri, USA) was used as a positive control. The flavonoid content was expressed in terms of quercetin equivalent $(\mathrm{mg} / \mathrm{g}$ of the extracted compound).

\section{Antisickling Activity}

The antisickling effect of the fruits was determined by the method of Adejumo et al (20). HbSS blood samples $(0.2 \mathrm{~mL})$ was pipetted into six test tubes followed by addition of $0.2 \mathrm{~mL}$ of the aqueous extracts and ethyl acetate fractions of unripe, partly ripe and fully ripe fruits were placed into six test tubes separately. The mixture was overlaid with $1 \mathrm{~mL}$ liquid paraffin (to exclude oxygen from the mixture) and incubated in a water bath at $37^{\circ} \mathrm{C}$ for 4 hours. Then $0.6 \mathrm{~mL}$ of freshly prepared $2 \%$ sodium metabisulphite (LOBA Chemie Pvt. Ltd., Mumbai, India) solution was added carefully under the liquid paraffin to the mixture using a syringe and needle. The solution was then mixed and incubated further for another 90 minutes at $37^{\circ} \mathrm{C}$ in a water bath. The experiment was set up in triplicates with a negative control test tube containing $0.2 \mathrm{~mL}$ phosphate-buffered solution $(0.005 \mathrm{M}, \mathrm{pH} 8.0)$ in place of the extract. After 90 minutes of incubation, liquid paraffin was carefully removed and the resultant mixture was fixed in $3 \mathrm{~mL}$ of $5 \%$ buffered formalin and kept at ambient temperature until ready for counting. Slides were prepared by placing a drop of the mixture on a clean glass slide and covering with a slip. The edges were sealed with vaseline after gentle pressing to remove the excess mixture. Prepared slides were incubated at $37^{\circ} \mathrm{C}$ for 30 minutes and viewed under a microscope. The percentage antisickling activity of each extract was calculated using the formula:

(\%) Antisickling activity $=$ Number of non-sickled cells $\times 100$ Total number of cells
Sickling-reversal Activity of the Extract

The sickle-cell reversal effect of the extracts was determined using the method described by Ogunyemi et al (21). $0.2 \mathrm{~mL}$ of HbSS blood sample was pipetted into six test tubes, and 0.2 $\mathrm{mL}$ phosphate-buffered solution (0.005M, pH 8.0) was added to each, the mixture was then covered with $1 \mathrm{~mL}$ liquid paraffin. $0.6 \mathrm{~mL}$ of $2 \%$ sodium metabisulphite solution was carefully introduced into the mixture under the liquid paraffin. The solution was mixed gently and then incubated at $37^{\circ} \mathrm{C}$ in a water bath for 90 minutes. At the end of the incubation period, $0.2 \mathrm{~mL}$ each of the aqueous extracts and ethyl acetate fractions of the fruits were added to each tube under the liquid paraffin and incubated for another four hours. The experiment was set up in triplicates with a negative control test tube containing 0.2 $\mathrm{mL}$ phosphate buffer solution in place of the extract. The liquid paraffin layer was carefully removed using a Pasteur pipette and $3 \mathrm{~mL}$ of $5 \%$ buffered formalin solution was added at the end of the 4-hour incubation. The solution was thoroughly mixed and kept at ambient temperature until ready for microscopic analysis. Slides were prepared by placing a drop of the solution on a clean glass slide and covering with a slip. The edges were sealed with Vaseline after gentle pressing to remove the excess mixture. The prepared slide was then incubated at $37^{\circ} \mathrm{C}$ for 30 minutes and viewed under a microscope. The percentage sickle cell reversal activity of each extract was calculated using the formula: (\%) Sickling-reversal activity $=$ Number of non-sickled cells $\times 100$ Total number of cells

\section{Results}

The phytochemical contents of $C$. papaya fruits at various stages of ripening are shown in Table 1. The percentage alkaloid composition of the partly ripe C. papaya fruit $(14.24 \pm 3.49 \%)$ was significantly lower $(p<0.05)$ than that of the unripe $(18.17 \pm 0.52 \%)$ and fully ripe $(19.29 \pm$ $2.50 \%)$ fruits. For tannin composition, there was a significant difference $(p<0.05)$ between the three fruits, with the fully ripe $C$. papaya fruit $(22.26 \pm 0.43 \mathrm{mg} \mathrm{CE} / 100 \mathrm{~g})$ having the highest tannin content, followed by the partly ripe fruit $(4.84 \pm 1.09 \mathrm{mg} \mathrm{CE} / 100 \mathrm{~g})$ and the unripe fruit $(1.25 \pm 0.66 \mathrm{mg} \mathrm{CE} / 100 \mathrm{~g})$ having the least. The total phenol composition for the fruits was found to be lower in the unripe fruit $(334.12 \pm 12.03 \mathrm{mg}$ $\mathrm{GAE} / 100 \mathrm{~g}$ ) as compared to the partly ripe $(450.90 \pm 13.83 \mathrm{mg} \mathrm{GAE} / 100 \mathrm{~g})$ and fully ripe $(448.29 \pm 18.61 \mathrm{mg} \mathrm{GAE} / 100 \mathrm{~g})$ fruits. There was no significant difference $(p>0.05)$ in the flavonoid 
and saponin concentrations of the fruit at different ripening stages.

Table 1: Phytochemical composition of unripe, partly ripe and fully ripe $C$. papaya fruit

\begin{tabular}{|c|c|c|c|}
\hline \multirow{2}{*}{ Phytochemical } & \multicolumn{3}{|c|}{ C. papaya fruit } \\
\hline & Unripe & Partly Ripe & Fully Ripe \\
\hline Alkaloid (\%) & $18.17 \pm 0.52^{b}$ & $14.24 \pm 3.49^{a}$ & $19.29 \pm 2.50^{\mathrm{b}}$ \\
\hline Saponin (\%) & $1.58 \pm 0.23^{a}$ & $1.66 \pm 0.37^{a}$ & $1.82 \pm 0.10^{\mathrm{a}}$ \\
\hline Tannin (mg CE/ 100 g) & $1.25 \pm 0.66^{a}$ & $4.84 \pm 1.09^{b}$ & $22.26 \pm 0.43^{c}$ \\
\hline Total Phenol (mg GAE/100 g) & $334.12 \pm 12.03^{a}$ & $450.90 \pm 13.83^{b}$ & $448.29 \pm 18.61^{\mathrm{b}}$ \\
\hline Flavonoid (mg QE/ $100 \mathrm{~g}$ ) & $14.69 \pm 1.71^{\mathrm{a}}$ & $18.14 \pm 1.69^{\mathrm{a}}$ & $15.87 \pm 1.08^{\mathrm{a}}$ \\
\hline
\end{tabular}

Figure 1. shows the antisickling effect of the aqueous extracts and ethyl acetate fractions of unripe, partly ripe and fully ripe C. papaya fruit. The control group had the lowest antisickling activity compared to the treatment groups. The ethyl acetate fractions of the unripe and partly ripe fruits had the highest antisickling effect of $62.72 \%$ and $68.11 \%$, respectively. The antisickling effect of the ethyl acetate fraction of the partly ripe fruit was significantly higher $(p=$ 0.02 ) than that of ethyl acetate fraction of the unripe $C$. papaya. In contrast, the aqueous extracts of the partly ripe and fully ripe fruits had the lowest antisickling activity among the treatment groups with no significant difference $(p$ $>0.05$ ) between the two fruits.

Figure 1: Antisickling effect of aqueous extracts and ethyl acetate fractions of unripe, partly ripe and fully ripe C. papaya fruit

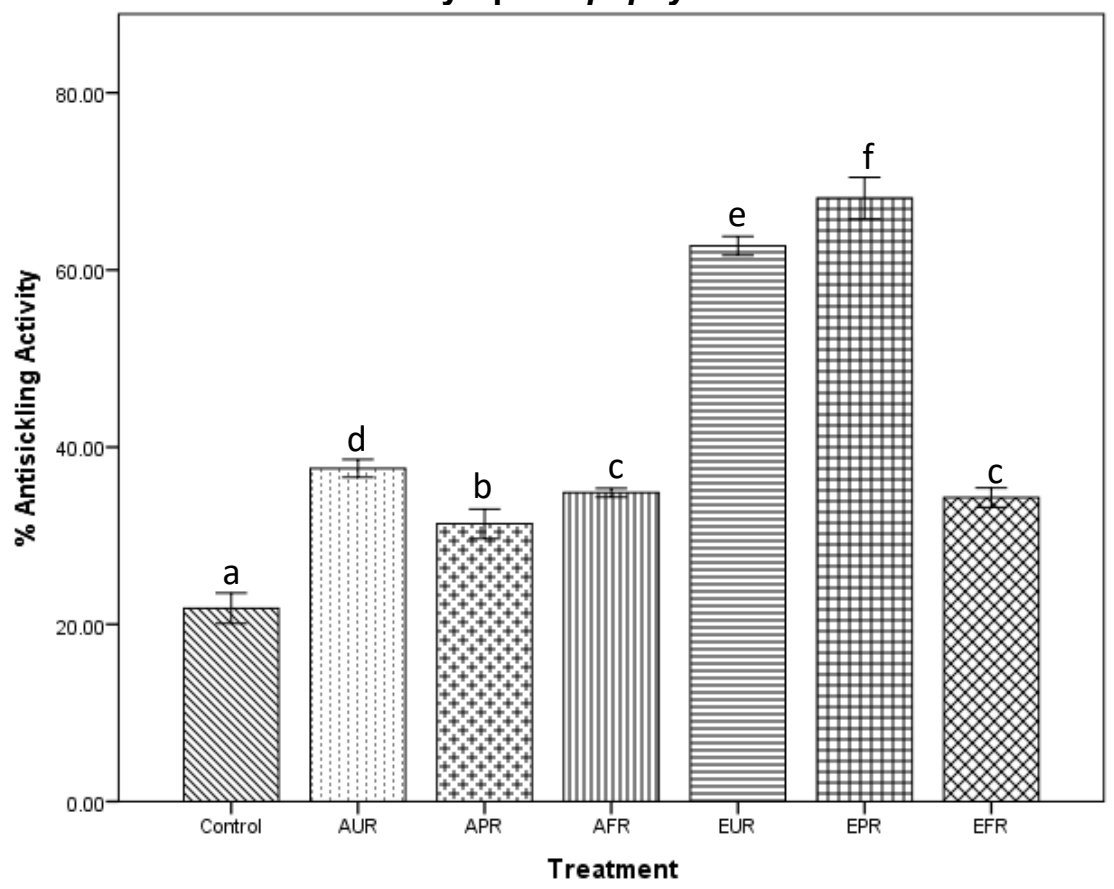

Bars with the same letters have no statistically significant difference at $p<0.05$.

AUR - Aqueous extract of unripe C. papaya; APR - Aqueous extract of partly ripe C. papaya;

AFR - Aqueous extract of fully ripe C. papaya; EUR - Ethyl acetate fraction of unripe C. papaya

EPR - Ethyl acetate fraction of partly ripe C. papaya; EFR - Ethyl acetate fraction of fully ripe C. papaya

Figure 2 shows the sickling-reversal activity of the aqueous extracts and ethyl acetate fractions at various ripening stages of the $C$. papaya fruit. All the treatment groups had higher sickling-reversal activities than the control group. The ethyl acetate fraction of the unripe and partly ripe fruits had the 
highest sickling-reversal activity of $40.40 \%$ and $47.47 \%$, respectively. Also, the sickling-reversal activity of ethyl acetate fraction of the partly ripe

Figure 2: Sickling-reversal activity of aqueous extracts and ethyl acetate fractions of unripe, partly ripe and fully ripe $C$. papaya fruit

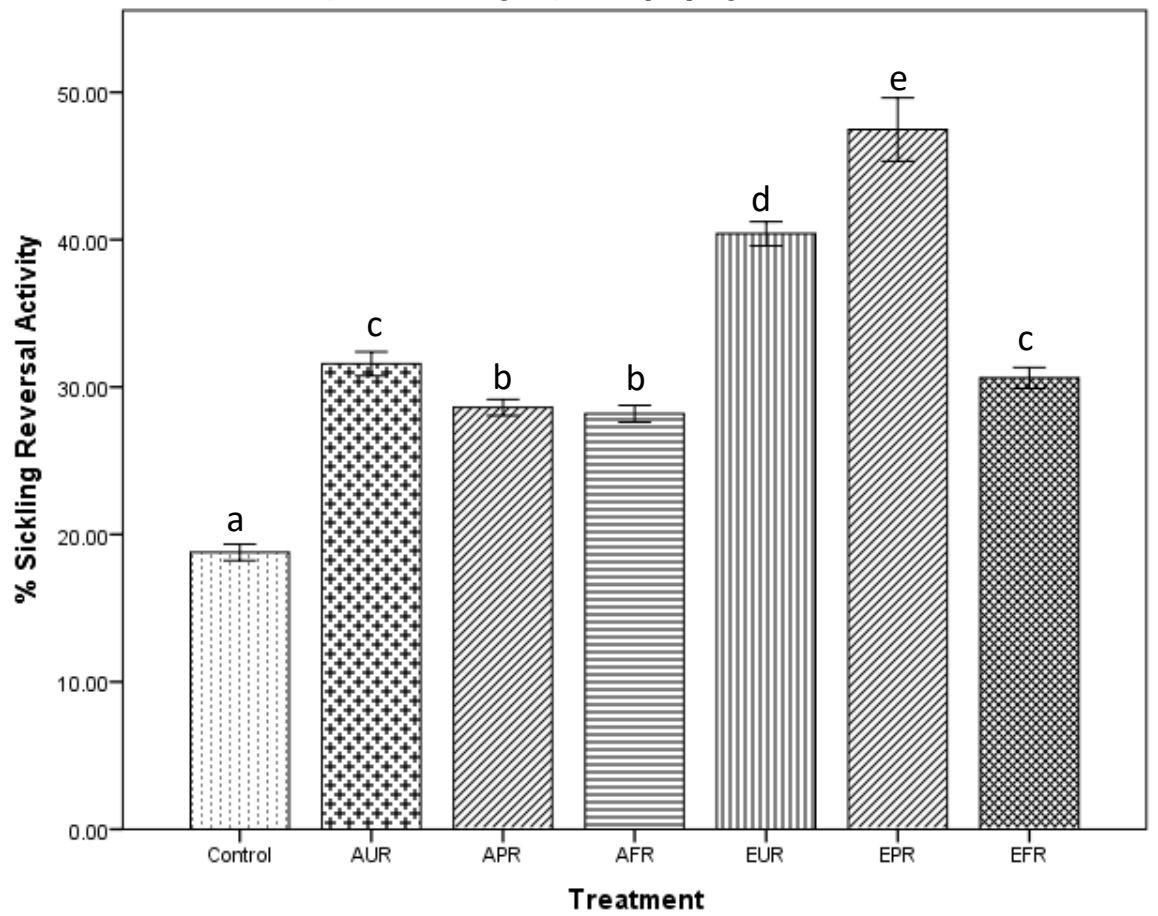

Bars with the same letters have no statistically significant difference at $p<0.05$.

AUR - Aqueous extract of unripe C. papaya; APR - Aqueous extract of partly ripe C. papaya;

AFR - Aqueous extract of fully ripe C. papaya; EUR - Ethyl acetate fraction of unripe C. papaya

EPR - Ethyl acetate fraction of partly ripe C. papaya; EFR - Ethyl acetate fraction of fully ripe C. papaya

\section{Discussion}

C. papaya fruit, at different ripening stages, contains phytochemicals such as alkaloid, saponin, tannin, phenol, and flavonoids. Previous studies have reported the presence of these phytochemicals in C. papaya fruit, stem, leaves, seeds, and bark $(22,23)$. These compounds have been reported to contain the active principle for plants containing antisickling agents (24).

Ibrahim et al (25) reported that antisickling activity of Hymenocardia acida Tul was found in the fractions containing flavonoids and saponin. Furthermore, flavonoids have been shown to protect against hemoglobin oxidation and other cellular modifications promoted by peroxides in SCD (26). Kumar and Pandey (27) reported that the functional hydroxyl groups in flavonoids mediate their antioxidant effects in sickle cells by scavenging free radicals and/or by chelating metal ions.

Hence, the results of this study are in congruence with earlier reports where Hymenocardia acida (25), Plumbago zeylanica (20), C. cajan leaf (10),
Zanthoxylum heitzii roots $(7,28)$, and unripe fruit, ${ }^{29}$ seeds and leaf extracts (30) of C. papaya have been screened for the presence of these phytochemicals. Each phytochemical is of specific importance in its application for the management of SCD in ethnomedicine. Alkaloids have been reported to show stimulatory effects on the nerves and also act as anticonvulsants and muscle relaxants (31). This property of alkaloids may help in the management of pain associated with vaso-occlusive crises in SCD. Saponins, phenols, and tannins have been found to possess antioxidant activities (32) which may help to prevent the generation of free radicals and prevent oxidative damage to cells and tissues in patients with SCD. The presence of these phytochemicals in the extracts and fractions of $C$. papaya fruit probably explains the reason for the antisickling properties elicited.

Oduola et al (13) reported that the ethyl acetate fraction of unripe C. papaya fruit contains an antisickling agent, which was identified as caricapinoside (8(2-0- $\beta-D-4,5$-anhydroglucitoyl 
$1 \rightarrow 2$ glucopyranosyl carbonyl) dibenzo [b,e] [1,4] dioxine-2-carboxylic acid). Findings from this present study revealed that the unripe, partly ripe, and fully ripe pulp of $C$. papaya have antisickling and sickling-reversal activities but the ethyl acetate fraction of partly ripe $C$. papaya possessed the highest antisickling activity when compared to other extracts and fractions of the unripe and fully ripe fruits. This finding suggests that the partly ripe fruit may also contain caricapinoside as previously reported for the unripe fruit (12), and perhaps at a higher concentration than the unripe $C$. papaya fruit. This could account for its effectiveness in preventing the sickling of erythrocytes on exposure to a sickling agent (sodium metabisulphite). This may also be the bioactive agent responsible for the sickling-reversal activity shown by the ethyl acetate fraction of the partly ripe $C$. papaya fruit which was significantly higher than that of the unripe fruit.

Findings from this study justify the use of $C$. papaya for the management of SCD by traditional healers. It may also route to the discovery of bioactive compounds that may be used in the development of drugs in the management of SCD, by medical practitioners which will be affordable and have very minimal or no side effects. However, this study is a preliminary investigation from which further studies will be designed to clarify the findings.

\section{Conclusion}

C. papaya fruit, at different stages of ripening, contains important phytochemicals at varying concentrations. Aqueous extracts and ethyl acetate fractions of $C$. papaya fruit showed antisickling and sickling-reversal activities. These activities may synergistically help to reduce the associated complications of sickle cell disease when consumed by affected individuals.

It is recommended that further research should be conducted to determine the presence and composition of caricapinoside in $C$. papaya fruit at different stages of ripening. Also, the mechanism(s) of action of the aqueous extracts and ethyl acetate fractions of $C$. papaya fruit at different stages of ripening should be investigated.

\section{Declarations}

Ethics approval and consent to participate

Ethics Approval for the study was obtained from the Babcock University Health Research Ethics
Committee with reference number: BUHREC104/19.

\section{Consent for publication}

The authors hereby give consent for the publication of our work under the creative commons CC Attribution-Noncommercial 4.0 license.

\section{Availability of data and materials}

The data and materials associated with this research will be made available by the corresponding author upon reasonable request.

Competing interests

The authors declare no conflict of interest.

\section{Funding}

The authors did not receive any funding for the research

\section{Authors' contributions}

All authors contributed equally to the design, methodology, data collection, write-up, and the final editing of the manuscript.

\section{Acknowledgment}

The authors acknowledge the laboratory technologists who assisted in the conduce $=\mathrm{t}$ of the research.

\section{References}

1. Patrick, TM, Alecia CN, Russell, EW. Current Management of Sickle Cell Anemia. Cold Spring Harbor Perspectives in Medicine. 2013;3: 1-18. https://doi.org/10.1101/cshperspect.a011817

2. Pauling L, Itano H. Sickle-cell anemia, a molecular disease. Science 1949; 110(2865): 543-548. https://doi.org/10.1126/science.110.2865.543

3. Acquaye CT, Young JD, Ellory JC. Mode of transport and possible mechanisms of action of L-phenylalanine benzyl ester as an antisickling agent. Biochim Biophys Acta. 1982;693(2): 407-416. https://doi.org/10.1016/0005-2736(82)90448$\underline{5}$

4. Heeney MM, Ware RE. Hydroxyurea for children with sickle cell disease. Pediatr Clin North Am. 2008;55: 483-501. https://doi.org/10.1016/j.pcl.2008.02.003

5. Oniyangi $O$, Omari A. Malaria chemoprophylaxis in sickle cell disease. Cochrane Database Syst. Rev. 2006;4: 
CD003489.

https://doi.org/10.1002/14651858.cd003489

6. Iyamu E, Turner E, Asakura T. In vitro effects of Niprisan (Nix - 0699): A naturally occurring, potent antisickling agent. Br. J. Haematol. 2002;118:

337-343.

https://doi.org/10.1046/j.1365-

2141.2002.03593.x

7. Onah JO, Akubue PI, Okide GB. The Kinetics of reversal of pre-sickled erythrocytes by the aqueous extracts of Cajanus cajan seeds. Phytother Res. 2002;16(8): 1-3. https://doi.org/10.1002/ptr.1026

8. Egunyomi A, Moody J, Eletu, O. Antisickling activities of two ethnomedicinal plant recipes used for the management of sickle cell anemia in Ibadan, Nigeria. Afr. J. 2009;8(1): 20-25.

9. Pauline N, Cabral B, Anatole P, Jocelyne A, Bruno, M, Jeanne, N. The in vitro antisickling and antioxidant effects of aqueous extracts Zanthoxyllum heitzii on sickle-cell disorder. BMC Complement Altern Med. 2013; 13(1):162. https://doi.org/10.1186/1472-688213-162

10. Parle M. Basketful benefits of Papaya. IRJP. 2011;2(7): 6-12.

11. Imaga N., Shaire E, Ogbeide, S. Akindele S. In vitro biochemical investigations of the effects of Carica papaya and Fagara zanthoxyloides on antioxidant status and sickle erythrocytes. AJBR. 2011;5(8): 226236.

12. Shen, YH, Yang FY, Lu, BG, Zhao, WW, Jiang $\mathrm{T}$, Feng $\mathrm{L}$, Chen $\mathrm{XJ}$, Ming R. Exploring the differential mechanisms of carotenoids biosynthesis in the yellow peel and re flesh of papaya. BMC Genomics. 2019;20(49): 1-11. https://doi.org/10.1186/s12864-018-5388-0

13. Oduola T, Adeniyi F, Ogunyemi E, Bello I, Idowu T. Haematological response to the intake of unripe Carica papaya fruit extract and the isolation and characterization of Caricapinoside: A new antisickling agent from the extract. Asian Journal of Pharmaceutical and Clinical Research. 2012;5(3):77-81.

14.Whitehead, E. Venepuncture. East Lancashire HC NHS Trust. 2010. [cited 2020 June 8]. Available from: www.eastlancsdue.nhs.uk/images/Venepunct ure.pdf

15. Oloyede OI. Chemical Profile of Unripe Pulp of Carica papaya. PJN. 2005;4(6): 379-381. https://doi.org/10.3923/pin.2005.379.381

16. Harborne J.B. Phytochemical methods, London. Chapman and Hall Ltd 1973,49-188.
17. Obadoni BO, Ochuko PO. Phytochemical studies and comparative efficacy of the crude extracts of some Homostatic plants in Edo and Delta States of Nigeria. Global J Pure Appl Sci. 2001;8b: 203-208. https://doi.org/10.4314/gipas.v8i2.16033

18. Singleton V, Orthofer R, Lamuela-Raventos R. Analysis of total phenols and other oxidation substrates and antioxidants by means of Folin-Ciocalteau's reagent. Method Enzymol 1999;299: 152-178. https://doi.org/10.1016/s00766879(99)99017-1

19. Chang, C, Yang, M, Wen, H, Chern, J. Estimation of total flavonoid content in propolis by two complementary colorimetric methods. J Food Drug Anal. 2002;10: 178182.

20.Adejumo OE, Ayoola MD, Kolapo AL, Orimoyegun VO. Antisickling activities of extracts of leaf, seed, and seed pod of Garcinia kola Heckel. Afr J Pharm Pharmacol. 2011;5(1): 48-52. https://doi.org/10.5897/ajpp10.052

21. Ogunyemi CM, Elujoba AA, Durosinmi MA. Antisickling properties of Carica papaya Linn. J. Nat. Prod. 2008;1: 56-66.

22. Abayomi FD, Nzewuji FO, Esan AM, Oyeleye SI, Adegbola VB. Phytochemical and antioxidant analysis of aqueous extracts of unripe pawpaw (Carica papaya Linn.) fruit's peel and seed. IJRRAS. 2016;27(3): 68-71.

23. Canini A, Alesiani D, D'Arcangelo G, Tagliatesta G. Gas chromatography-mass spectrometry analysis of phenolic compounds from Carica papaya L. leaf. J. Food Compos. Anal. 2007;20(7): 584-590. https://doi.org/10.1016/j.jfca.2007.03.009

24. Oyenike MA, Akpan HB. Otulana JO, Adefule AK, Adedokun KA, Suleiman IE, et al. In vitro anti-depranocytary (anti-sickle cell anemia) and membrane stability potential of mishenland polyherbal extracts on sickle red blood cells. IJBR. 2018; 9(11):373-379. https://doi.org/10.4103/ejh.ejh 3318

25. Ibrahim, H, Sani F, Danladi B, Ahmadu A. Phytochemical and antisickling studies of the leaves of Hymenocardia acida Tul (Euphorbiaceae). PJBS. 2007;10: 788-791. https://doi.org/10.3923/pibs.2007.788.791

26. Kiefmann R, Rifkind JM, Nagababu E, Bhattacharya J. Red blood cells induce hypoxic lung inflammation. Blood. 2008;111(10): 5205-5214. https://doi.org/10.1182/blood-2007-09$\underline{113902}$ 
27.Kumar S, Pandey AK. Chemistry and biological activities of flavonoids: an overview. The scientific world journal. 2013 Oct;2013;116.

28. Eke ON, Augustine AU, Ibrahim HF. Qualitative analysis of phytochemicals and antibacterial screening of extracts of Carica papaya fruits and seeds. Int $\mathrm{J}$ Mod Chem. 2014;6:48-56.

29. Oduola T, Adeniyi FA, Ogunyemi EO, Bello IS, Idowu TO. Antisickling agent in an extract of unripe pawpaw (Carica papaya): is it real? African Journal of Biotechnology. 2006;5(20).
30.Imaga NA, Adepoju OA. Analyses of antisickling potency of Carica papaya dried leaf extract and fractions. J. Pharmacognosy Phytother. 2009;2(7): 97-102.

31.Leitzmann C. Characteristics and health benefits of phytochemicals. Complementary Medicine Research. 2016;23(2):69-74.

32.Dai J, R. J. Mumper R. Plant phenolics: Extraction, analysis, and their antioxidant and anticancer properties. Molecules. 2010;15: 7313-7352.

https://doi.org/10.3390/molecules 15107313 